\title{
Pleural lymphoma in a patient presenting with malabsorption: an illustration of the clinicopathological behaviour in a case of enteropathy associated $\mathrm{T}$ cell lymphoma
}

\author{
G J Doyle, J D G Rose, P J L Kesteven
}

\begin{abstract}
A case of enteropathy associated $\mathbf{T}$ cell lymphoma (EATCL) is described, which was diagnosed by biopsy of a lymphomatous pleural mass. Retrospective radiological review showed that this lesion had been present when an initial diagnosis of coeliac disease had been made 12 months previously and a detailed description of the natural history of the lymphoma during this period was thus available. The findings show that EATCL may behave in an indolent fashion and masquerade as coeliac disease, delaying the correct diagnosis. The relation of this disorder with coeliac disease and lymphocytic gastritis is discussed with reference to recent published works. (Gut 1993; 34: 1463-1466)
\end{abstract}

The cause and definition of enteropathy associated $\mathrm{T}$ cell lymphoma (EATCL) and its relation to coeliac disease has been the subject of much debate recently. This is centred around the question of whether or not $T$ cell lymphoma may be a cause or an effect of coeliac disease. The traditional view that EATCL is a complication of coeliac disease ${ }^{1}$ is supported by new immunohistochemical evidence that both diseases have similar subsets of intestinal mucosal $\mathrm{T}$ cells. ${ }^{2}$ It has been argued, however, that in some cases of adult onset 'coeliac' disease the histological findings of villous atrophy, crypt hyperplasia, and intra-epithelial lymphocytosis may be a response to low grade lymphomatous infiltration. ${ }^{3}$ Because coeliac disease may be asymptomatic ${ }^{4}$ it is difficult to prove that a monoclonal lymphocytic intestinal infiltrate can develop in previously normal bowel.

Lymphocytic gastritis is a recently described entity characterised by a dense epithelial lymphocytic infiltration ${ }^{5}$ the pathogenesis of which is incompletely understood. It has been associated with coeliac disease, small bowel lymphoma, ${ }^{6}$ and Menetrier's disease. ${ }^{7}$ In one report the subset of $\mathrm{T}$ cells present differed from those found in coeliac disease in having low percentage of $\gamma / \delta \mathrm{T}$ cells. ${ }^{7}$ Some take the view that it may be a common morphological manifestation of more than one disease. ${ }^{67}$

This report describes the case of a patient who was initially diagnosed and treated as having coeliac disease and lymphocytic gastritis but who responded poorly to a gluten free diet. A diagnosis of $T$ cell lymphoma was made by pleural biopsy one year later.

\section{Case report}

A 74 year old man presented in October 1990 with a two year history of intermittent diarrhoea and weight loss. Investigations showed a raised mean corpuscular volume (MCV $-114 \mathrm{fl})$, low serum B12 (150 ng/l), normal 200-1000), and folate $(1 \cdot 2 \mu \mathrm{g} / \mathrm{l}$, normal $2-14)$. Haematological parameters were otherwise normal. Liver function was normal. Chest $x$ ray showed evidence of previous tuberculosis and some pleural thickening at the left base, which was thought likely to be long standing (Fig 1). Barium enema was normal. Gastroscopy showed a nodular gastric mucosa with apthous ulceration and superficially normal duodenal mucosa. Gastric biopsy showed a lymphocytic gastritis and duodenal biopsy showed partial villous atrophy with a mixed severe mononuclear cell

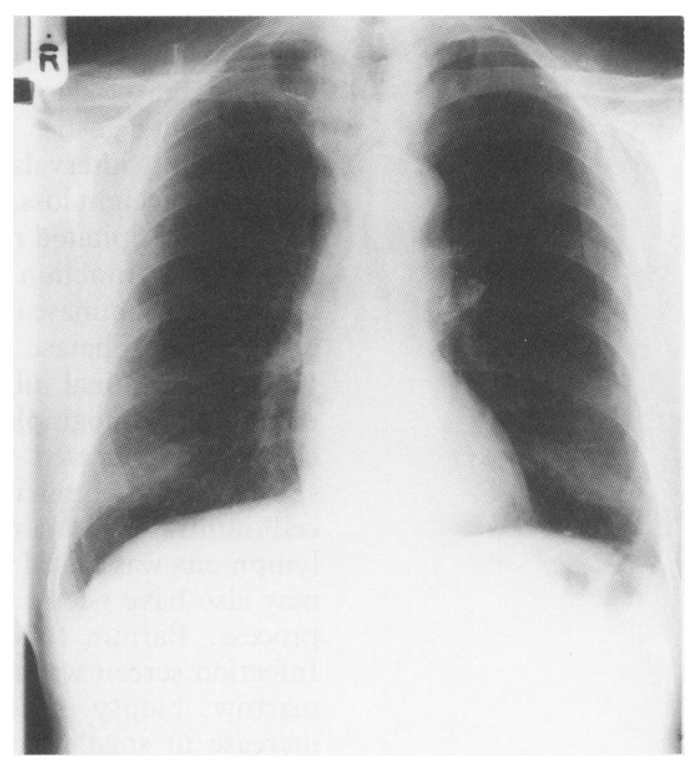

Figure 1: Chest $\mathrm{x}$ ray at presentation showing blunting of the left costophrenic angle.

Departments of
Radiology and
Haematology, Freeman
Hospital, Newcastle
upon Tyne
G J Doyle
J D G Rose
P J L Kesteven
Correspondence to:
Dr J D G Rose, Department of
Radiology, Freeman Hospital,
Newcastle upon Tyne
NE7 7DN.
Accepted for publication
4 March 1993




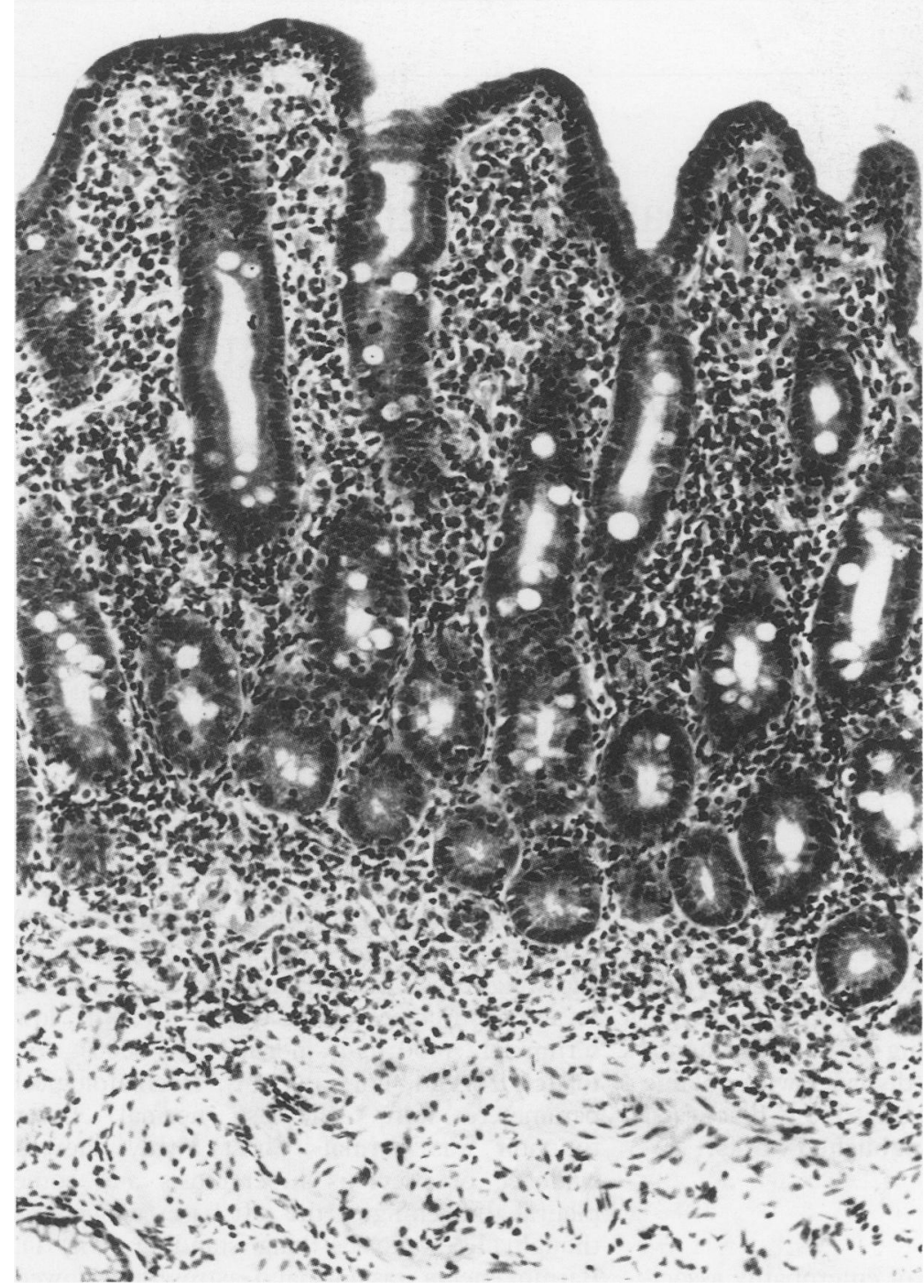

Figure 2: Duodenal biopsy specimen showing partial villous atrophy and intense intraepithelial mononuclear cell infiltrate.

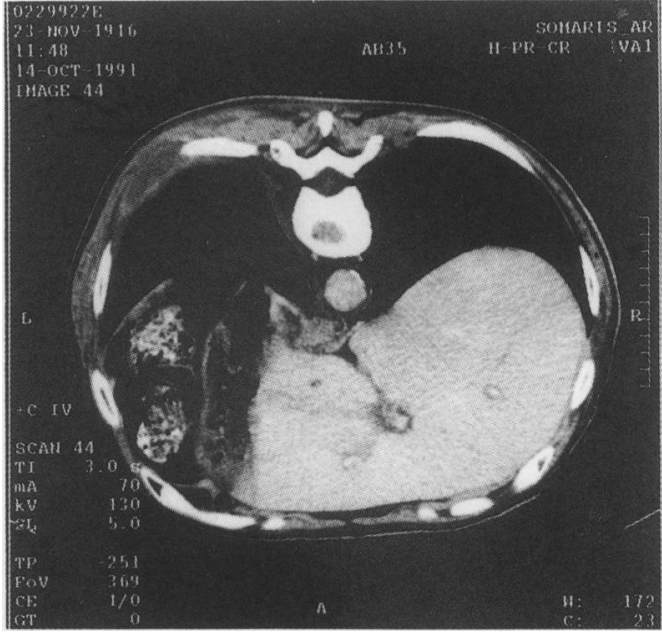

Figure 3: Transverse computed tomography scan of the chest during IV contrast showing a rim enhancing left sided pleura associated mass that corresponds with the area of pleural thickening seen on chest $\mathrm{x}$ ray.

ing at the left lung base in an area corresponding to that previously noted on a chest $x$ ray (Fig 3 ). A biopsy specimen of this lesion showed infiltration of the chest wall by malignant mononuclear cells of $\mathrm{T}$ cell phenotype consistent with a high grade non-Hodgkin's lymphoma (Fig 4). Because of the poor response to gluten free diet and the presence of lymphoma it seemed reasonable to consider that the malabsorption was as a result of an enteropathy associated with the lymphoma (EATCL) rather than simple coeliac disease.

The patient then received 'B-CHOP' chemotherapy. Each course of 'B-CHOP' consists of intravenous bleomycin, vincristine, cyclo-

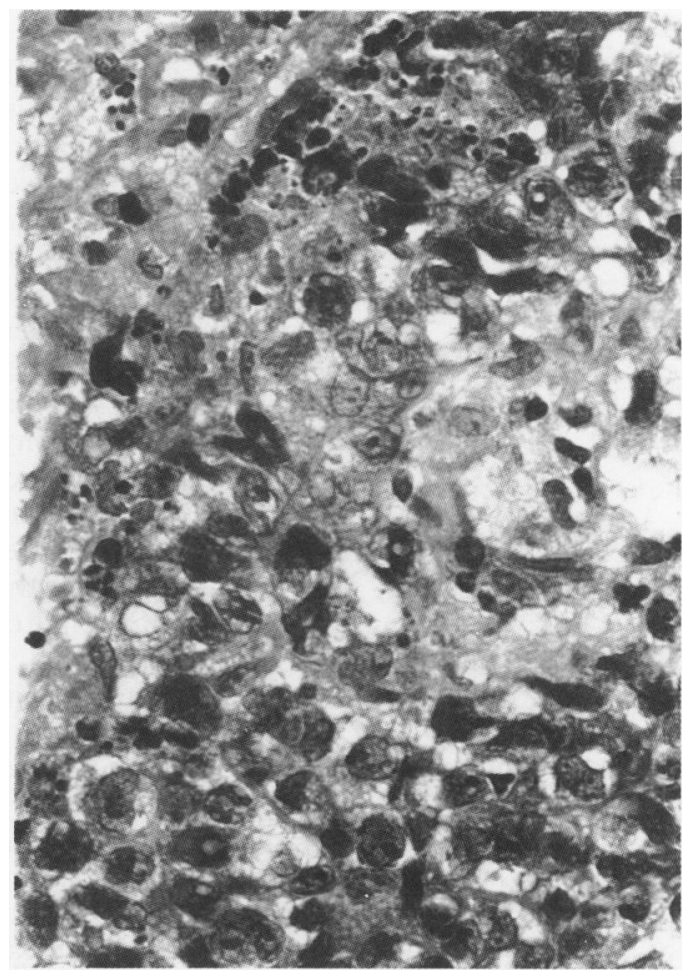

Figure 4: Pleural biopsy specimen showing a malignant mononuclear cell infiltrate. The malignant cells have large mononuclear cell infiltrate. The malignant cells have large nucleoli. Immunohistochemistry showed a T cell phenotype. 

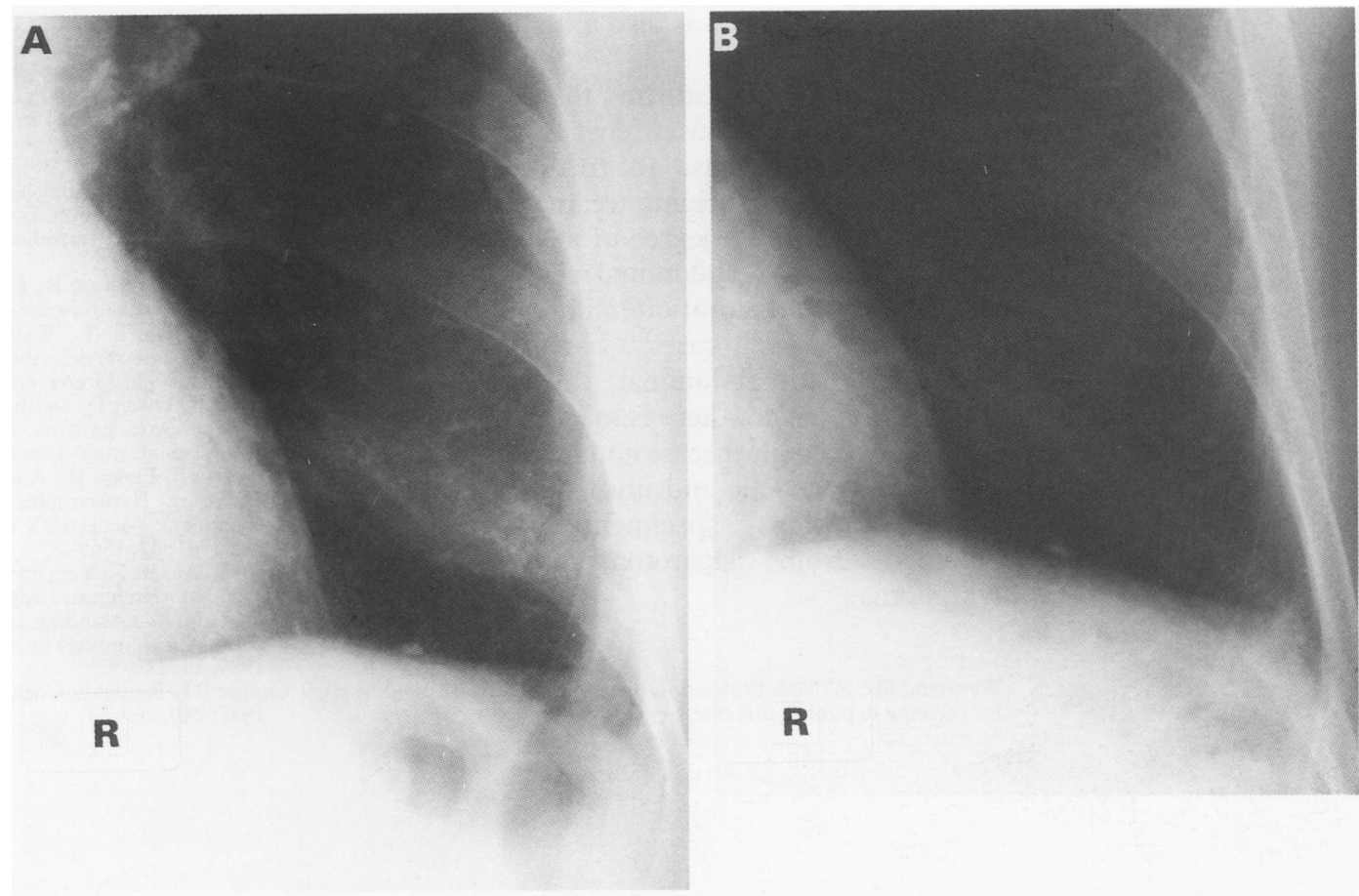

Figure 5: (A) left costophrenic angle before B-CHOP chemotherapy; $(B)$ left costophrenic angle after three courses of chemotherapy.

phosphamide, and adriamycin on day 1 with oral prednisolone on days $1-5$. There is a course option at four weeks depending on the response of the lymphoma and the extent of bone marrow suppression that is induced. Computed tomography after three courses of chemotherapy showed that the pleural mass had reduced in size. This reduction in pleural thickening could also be seen on the chest $x$ ray (Fig 5) making it very likely that the pleural thickening noted initially in October 1990 and thought then to be unimportant was neoplastic from the outset. Unfortunately the chemotherapy was poorly tolerated, the patient went into a gradual decline, and died in a hospice three months later. Postmortem examination was refused.

\section{Discussion}

This patient presented with malabsorption and small bowel biopsy specimens were consistent with a diagnosis of coeliac disease. The subsequent biopsy of a lymphomatous pleural plaque, visible on previous radiographs, permitted the retrospective deduction of lymphoma at initial presentation. This case is similar to that of Wright $e a^{3}$ in that none of the intestinal tissue provided morphological evidence of lymphoma but differs in the unusual finding of a high grade lymphoma in the pleural lesion. Further similarities can be drawn with two cases described by Wolber, ${ }^{6}$ which had lymphocytic gastritis, small bowel intraepithelial lymphocytosis, and morphologically detectable $\mathrm{T}$ cell lymphoma of the small bowel.

A valuable feature of our case is that it provides a detailed profile of the natural history of EATCL over a period of 12 months from initial presentation to the introduction of chemotherapy. This suggests that EATCL may behave in an apparently indolent fashion with a very slow change in pathological state over many months as measured by clinical state, serial upper gastrointestinal biopsy, radiography, haematology, and biochemistry results. It is also of interest that the pleural lesion, morphologically a high grade lymphoma when biopsied, showed no significant increase in size during the year after presentation. There was some progression of the disease, however, over this period as shown by the slow deterioration in general condition and liver function. Although we have not investigated the clonality of the T cells infiltrating the gut one possibility is that these represented epitheliotropic 'transitional' or 'end' cell phases of the same cell line present in the pleural lesion. This may partly explain the lack of change in the appearance of the duodenal mucosa on serial biopsy in this condition. We consider it to be most unlikely that the pleural lesion is the site of origin of this lymphoma because of the extensive lymphocytic infiltration elsewhere, the long history of bowel symptoms, and the similarity with other described cases. ${ }^{34}$ Primary pleural lymphoma has been described, particularly in Japan ${ }^{8}$ but is said to arise most frequently from old inflammatory pleural disease, is usually of B cell type and is usually localised to the pleura.

The conventional view would be that our patient had asymptomatic coeliac disease and developed a lymphoma, which precipitated the initial presentation. The alternative view that the intestinal lymphoma developed as a primary event two years before presentation seems possible in view of the indolent nature of the disease and subsequent findings.

Clearly the combination of malabsorption with small bowel villous atrophy and lymphocytic infiltration is not specific for coeliac disease because EATCL may present in similar fashion. It is probable that the lymphocytic gastritis 
present in this case was also a manifestation of lymphoma.

These findings reaffirm the maxim that patients with adult onset 'coeliac' disease who show a poor response to treatment or who deteriorate when receiving treatment should be viewed with a high degree of suspicion. Small bowel biopsy and abdominal computed tomography are essential but often unhelpful in early diagnosis. ${ }^{9}$ In such cases a careful search for secondary extra-abdominal disease may be worthwhile. Unless there is macroscopic, radiologically detectable disease it may be necessary to perform cytogenetic and immunohistochemical studies on biopsy specimens, possibly even obtained from laparotomy, ${ }^{3}$ to exclude lymphoma.

We would like to thank Professor O James, and Dr M Bassendine for agreeing to publish this case.
1 Swinson CM, Slavin G, Coles EC, Booth CC. Coeliac disease and malignancy. Lancet 1983; i: 111-5.

2 Spencer J, MacDonald TT, Diss TC, Walker-Smith JA Ciclitira PJ, Isaacson PG. Changes in intraepithelial lymphocyte subpopulations in coeliac disease and enteropathy associated $T$ cell lymphoma (malignant histiocytosis of intestine). Gut 1989; 30: 339-46.

3 Wright DH, Jones DB, Clark H, Mead GM, Hodges E, Howell WM. Is adult-onset coeliac disease due to a low grade lymphoma of intraepithelial lymphocytes? Lancet 1991; 337 . lymphom $1373-4$.

4 Stokes PL, Ferguson R, Holmes GKT, Cooke WT. Familial aspects of coeliac disease. Qf Med 1976; 45: 567-82.

5 Haot J, Hamichi L, Wallez L, Mainguet P. Lymphocytic gastritis: a newly described entity: a retrospective endoscopic and histological study. Gut 1988; 29: 1258-64.

6 Wolber R, Owen D, DelBuono L, Appelman H, Freeman H. Lymphocytic gastritis in patients with celiac sprue or

7 Mosnier JF, Flejou JF, Amouyal G, Gayet B, Molas G, Henin $\mathrm{D}$, et al. Hypertrophic gastropathy with gastric adeno$\mathrm{D}$, et al. Hypertrophic gastropathy with gastric adenoGut 1991; 32: 1565-7.

8 Iuchi K, Aozasa K, Yamamoto S, Mori T, Tajima K, Minato K, et al. Non-Hodgkins lymphoma of the pleural cavity develop ing from long-standing pyothorax. Summary of clinical and pathological findings in thirty-seven cases. Fpn $\mathcal{F}$ Clin Oncol 1989; 19: 249-57.

9 Cooper BT, Read AE. Coeliac disease and lymphoma. $Q \mathcal{F} M e d$ 1987; 240: 269-74. 